\title{
UNCERTAINTIES OF GEODETIC VELOCITIES FROM PERMANENT GPS OBSERVATIONS: THE SUDETEN CASE STUDY
}

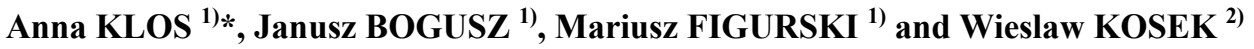 \\ ${ }^{1)}$ Faculty of Civil Engineering and Geodesy, Military University of Technology, 00-908 Warsaw, Kaliskiego St. 2, Poland \\ ${ }^{2)}$ University of Agriculture, Environmental Engineering and Land Surveying, Poland
}

*Corresponding author's e-mail: aklos@wat.edu.pl

\begin{tabular}{l} 
ARTICLE INFO \\
\hline Article history: \\
Received 25 January 2014 \\
Accepted 25 March 2014 \\
Available online 7 May 2014 \\
\hline
\end{tabular}

\section{Keywords:}

GPS

Noises

ASG-EUPOS

Sudeten area

MLE

\begin{abstract}
The assumption that the GPS-derived coordinate time series behave like the white noise leads to the underestimation of the velocity uncertainties. The permanent stations velocities are required nowadays with the stability at the level of $0.1 \mathrm{~mm} / \mathrm{year}$ in case of using them to the kinematic reference frame realization or numerous geodynamic interpretations. Therefore, it is required to know which kind of noise models describes the time series of geodetic coordinates better. These noises can be the effect of e.g. mismodelled satellite orbits or improperly mounted antennae. In the following paper, three combinations of noise models were assumed: the white noise model only, to show how the omitting of correlations in the stochastic part of the GPS time series underestimates the velocity uncertainties; the combination of the white plus flicker plus randomwalk noise to estimate which of the power-law noises with the known spectral index prevails in the GPS time series; and the combination of the white plus power-law noise to estimate which coloured noise fits the stochastic part the best. We analyzed more than 40 stations (belonging to the ASG-EUPOS and EPN networks) with 5 years of observations from the area of Sudeten. The results show that the amplitudes of the white noise for the assumption of white noise only model range from 0.6 to $2 \mathrm{~mm}$ for the horizontal (North and East) components and from 2 to $8 \mathrm{~mm}$ for the vertical (Up) component, while the velocity uncertainties range from 0.01 to $0.13 \mathrm{~mm} /$ year for the horizontal velocities and from 0.04 to 0.24 for the vertical one. For the combination of the white, flicker and random-walk noise, the white noise is at the same level in the entire analyzed area, while the flicker noise prevails over other kinds of noise for all components. For the North and East its amplitude ranges from 2 to $5 \mathrm{~mm} * \mathrm{yr}^{-0.25}$, while for the $\mathrm{U}$ component it is 2-3 times larger. Here, the uncertainty of permanent stations velocity ranges from $0.1 \mathrm{~mm} /$ year for the horizontal components to even $1.1 \mathrm{~mm} /$ year for the vertical one, which is over 10 times larger than the assumed level of stability of permanent stations velocity. For the last combination, the obtained spectral indices range from -1.6 to -0.4 for the horizontal components and from -1.0 to -0.4 for the vertical component, which confirms the prevalence of fractional white and Brownian motion quite close to flicker noise with amplitudes of power-law noise of 2$5 \mathrm{~mm} * \mathrm{yr}^{r / 4}$ and $4-12 \mathrm{~mm} * \mathrm{yr}^{r / 4}$, respectively. For this combination, the errors of the estimated velocities reach in the most extreme case even $0.8 \mathrm{~mm} /$ year for the Up component, which is 8 times greater than the required stability level.
\end{abstract}

\section{INTRODUCTION}

The reliable velocities of the permanent GNSS stations are currently used for the interpretation and geodynamic analyses as well as the kinematic reference frames realization. For these applications, they are required to be stable at the level of $0.1 \mathrm{~mm} /$ year (Gross et al., 2009). The velocities are commonly determined by means of the least squares (LS) method directly from the changes of the geodetic coordinates recorded at the permanent GPS stations by fitting a linear trend into the time series. Each of the station coordinates time series includes a deterministic part from which the seasonal components may be well modelled by means of various methods, e.g. the LS method, wavelet decomposition or the Singular Spectrum Analysis (e.g. Broomhead and King, 1986; Allen and Robertson, 1996). It also includes a stochastic part which is considered as the observational time-correlated or uncorrelated noise.
Many geophysical processes are well described by the power-law noise for which the spectral index $\kappa$ usually ranges from -3 to -1 (Agnew, 1992). Integer values of the spectral index indicate characteristic kinds of noises. Spectral index,$k=0$ " means that the stochastic part of the time series maps the white noise, ,,$k=1$ " means the flicker noise, while,$k=2$ " means the random-walk noise. It is commonly recognized that noises in the GPS observations result from the mismodelling of satellite orbits, the Earth Orientation Parameters, atmospheric effects or improper antennae mounting. Noises in the GPS observations may be described by means of various models, including: the power-law, white, flicker or random-walk noise (e.g. Johnson and Agnew, 1995; Williams et al., 2004; Beavan, 2005; Hill et al., 2009; Bogusz and Kontny, 2011; Wang et al., 2012; Langbein, 2012), First Order Gauss-Markov (FOGM) (e.g. Williams and Willis, 2006; Langbein, 2008; Ji and Herring, 2013), 


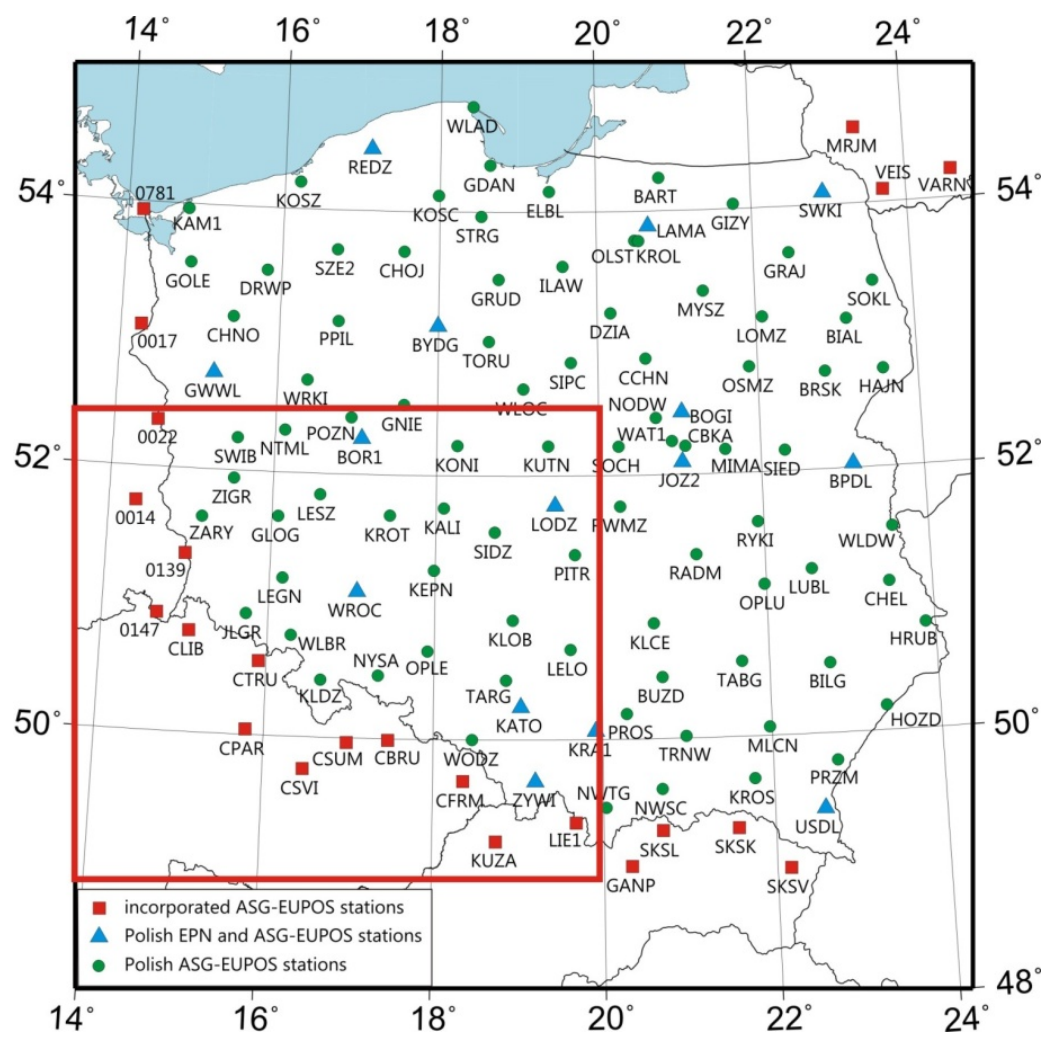

Fig. 1 The ASG-EUPOS network and selected EPN stations. The box indicates the Sudeten and adjacent areas from which the data were used for analyses.

Generalized Gauss-Markov (GGM) or Band-Pass (BP). In papers published so far, it is indicated that the best model to describe the stochastic part of the GPS time series is the power-law noise. Mao et al. (1999) analyzed daily data of 23 permanent stations situated worldwide using two noise models - the white with flicker noise and the white with flicker and randomwalk noise. They found out that a combination of white and flicker noise provides the best description of noise characteristics for all three components N, E, $\mathrm{U}$ of the station positions. However, they also proved that the amplitudes of both white and flicker noise are the smallest for the North component and the largest for the Up one. Williams et al. (2004) analyzed 414 stations from GPS solutions and they found that for stations worldwide noises are described in the best way by a combination of white plus flicker noise with an amplitude at the level of a few millimetres for the horizontal components and even $20 \mathrm{~mm}^{*} \mathrm{yr}^{-0.25}$ for flicker noise for the vertical component. Kenyeres and Bruyninx (2009) examined more than 190 EPN permanent stations with the Maximum Likelihood Estimation in CATS software. They focused on the noise and harmonic analyses which showed the presence of coloured noise (close to flicker one) and moderate seasonal amplitudes in the EPN time series. This paper is focused on the analysis of noise characteristic for stations situated in the region of the Sudeten with adjacent areas. Moreover, the influence that the specific combinations of noises have on the value of permanent stations velocity uncertainties was also shown.

\section{GPS DATA}

The Centre of Applied Geomatics (CAG) that operates at the Military University of Technology is one of the 16 EPN (EUREF Permanent Network) independent Local Analysis Centres (MUT LAC). It processes data from more than 110 stations evenly distributed throughout Europe. MUT LAC processes also data from the ASG-EUPOS which is the Polish active geodetic network (Bosy et al., 2007; 2008). The GPS data processing is implemented in the Bernese version 5.0 (Dach et al., 2007) with the consistent assumptions and models appointed for the EPN (Bruyninx et al., 2009). The datum and reference solution were taken from the previous research on the ASG-EUPOS-based reference frame maintenance (Szafranek et al., 2013). The ITRF2008 (Altamimi et al., 2011) coordinates were transformed into topocentric North, East and Up components and it covers the period from 1465 to 1729 GPS weeks (5 years). Data from more than 40 permanent GPS stations located at the Sudeten and adjacent areas (Figure 1), were taken for the research.

The outliers were removed by means of the median absolute deviation criterion (MAD; Mosteller and Tukey, 1977; Sachs, 1984). It has an advantage in comparison with the commonly used algorithm of three standard deviations $(3 \sigma)$ because it is robust to 
the outliers. The STARS algorithm (Sequential t-test Analysis of Regime Shifts; Rodionov, 2004; Rodionov and Overland, 2005), which is a combination of the t-Student test and the standard deviation test, was used for the automatic detection and removal of offsets from the time series. The removed offsets were checked manually, so no blind-usage of the results was done. A great variety of automated methods was compared with the manual removal by Gazeaux et al. (2013). They showed how the appropriate choice of the method of the offsets removal influences any further determinations and analyses.

\section{METHODS AND NOISE ANALYSIS}

Let us consider the time series of the site coordinates as a sum of an initial value $x_{0}$, trend $v_{x}$ (interpreted as the permanent GPS station velocity), $A_{A}$ and $A_{S A}$ being the amplitudes of annual and semiannual terms, $\phi_{A}$ and $\phi_{S A}$ - the phase shifts of annual and semi-annual terms and a stochastic part $\varepsilon_{x}(t)$ :

$$
x(t)=x_{0}+v_{x} \cdot t+A_{A} \cdot \sin \left(\frac{2 \pi}{y} \cdot t+\varphi_{A}\right)+A_{S A} \cdot \sin \left(\frac{4 \pi}{y} \cdot t+\varphi_{S A}\right)+\varepsilon_{x}(t)
$$

If we implement the linear approximation of the time series, the above equation for $x_{0}$ and $v_{x}$ is solved by means of the LS method:

$\hat{\mathbf{y}}=\left[\mathbf{A}^{T} \mathbf{C}_{\mathbf{x}}^{-1} \mathbf{A}\right]^{-1} \mathbf{A}^{T} \mathbf{C}_{\mathbf{x}}^{-1} \mathbf{x}$

where:

$\hat{\mathrm{y}}=\left[x_{0}, v_{x}, A_{A}^{I}, A_{A}^{o}, A_{S A}^{I}, A_{S A}^{o}\right]^{T}$, with $A_{A}^{I}, A_{A}^{o}, A_{S A}^{I}, A_{S A}^{o}$ being the annual and semiannual periodic terms in-phase $(I)$ and out of phase $(O)$, respectively,

$$
\mathbf{x}=\left[x_{t_{1}}, \ldots, x_{t_{N}}\right]^{T}, \quad \mathbf{A}=\left[\begin{array}{cccccc}
1 & t_{1} & \sin \left(2 \cdot \pi \cdot t_{1}\right) & \cos \left(2 \cdot \pi \cdot t_{1}\right) & \sin \left(4 \cdot \pi \cdot t_{1}\right) & \cos \left(4 \cdot \pi \cdot t_{1}\right) \\
\cdots & \ldots & \cdots & \cdots & \ldots & \ldots \\
1 & t_{N} & \sin \left(2 \cdot \pi \cdot t_{N}\right) & \cos \left(2 \cdot \pi \cdot t_{N}\right) & \sin \left(4 \cdot \pi \cdot t_{N}\right) & \cos \left(4 \cdot \pi \cdot t_{N}\right)
\end{array}\right] \text {, and } \mathbf{C}_{\mathrm{x}} \text { is the }
$$

covariance matrix of the observation $x, N$ is the length of time series, the covariance matrix of $\hat{\mathrm{y}}$ is determined using:

$$
\mathbf{C}_{\hat{\mathbf{y}}}=\left[\mathbf{A}^{\mathrm{T}} \mathbf{C}_{\mathbf{x}}^{-1} \mathbf{A}\right]^{-1}
$$

In this research, the character of the stochastic part of the GPS time series was determined by means of the Maximum Likelihood Estimation (MLE) (Langbein and Johnson, 1997) using the CATS software (Williams, 2008). The MLE is the most often applied method for noises determination in the GPS observations (e.g. Williams et al., 2004; Beavan, 2005; Teferle et al., 2008; Bos et al., 2008) because it is the most precise one (Beran, 1994). It is defined by the following equation:

$$
\operatorname{lik}\left(\hat{\mathbf{v}}, \mathbf{C}_{\mathrm{x}}\right)=\frac{1}{(2 \cdot \pi)^{\mathrm{N} / 2} \cdot\left(\operatorname{det} \mathrm{C}_{\mathrm{x}}\right)^{1 / 2}} \cdot \exp \left(-0.5 \cdot \hat{\mathbf{v}}^{\mathrm{T}} \cdot \mathbf{C}_{\mathrm{x}}^{-1} \cdot \hat{\mathbf{v}}\right)
$$

where lik is the likelihood function, $\hat{\mathbf{V}}$ is the time series residua matrix, $\mathbf{C}_{\mathbf{x}}$ is the covariance matrix of the observations. This covariance matrix $\mathbf{C}_{\mathbf{x}}$ has a direct influence on the uncertainties of the linear parameters determined from the time series (taken directly into the solution of the assessment of the velocity or trend $v_{x}$ and initial value $x_{0}$ ), and it may represent various kinds of noises occurring in time series. It may be the Gaussian white noise or a time-correlated coloured noise. We assumed three kinds of noise models: the white noise (5), the combination of white, flicker and random-walk noise (6) and the combination of white and power-law noise (7) for which the covariance matrices are created by means of:

$$
\begin{aligned}
& \mathbf{C}_{\mathbf{x}}=\mathbf{a}^{2} \cdot \mathbf{I} \\
& \mathbf{C}_{\mathbf{x}}=\mathbf{a}^{2} \cdot \mathbf{I}+\mathbf{b}_{\mathrm{FL}}^{2} \cdot \mathbf{J}_{\mathrm{FL}}+\mathbf{b}_{\mathrm{RW}}^{2} \cdot \mathbf{J}_{\mathrm{RW}} \\
& \mathbf{C}_{\mathbf{x}}=\mathbf{a}^{2} \cdot \mathbf{I}+\mathbf{b}_{\mathrm{PL}}^{2} \cdot \mathbf{J}_{\mathrm{PL}}
\end{aligned}
$$

where $a$ is the amplitude of white noise, $\mathbf{I}$ is unit matrix of the $N \mathrm{x} N$ dimension ( $N$ is the series length), $b$ are the coloured noise amplitudes: flicker, random-walk or power-law, while $\mathbf{J}$ denotes the covariance matrix for the specific kinds of coloured noises. The above mentioned combinations of noises enabled to present the values of the permanent GPS stations velocities and their uncertainties for various assumptions of the character of the stochastic part of the time series. 

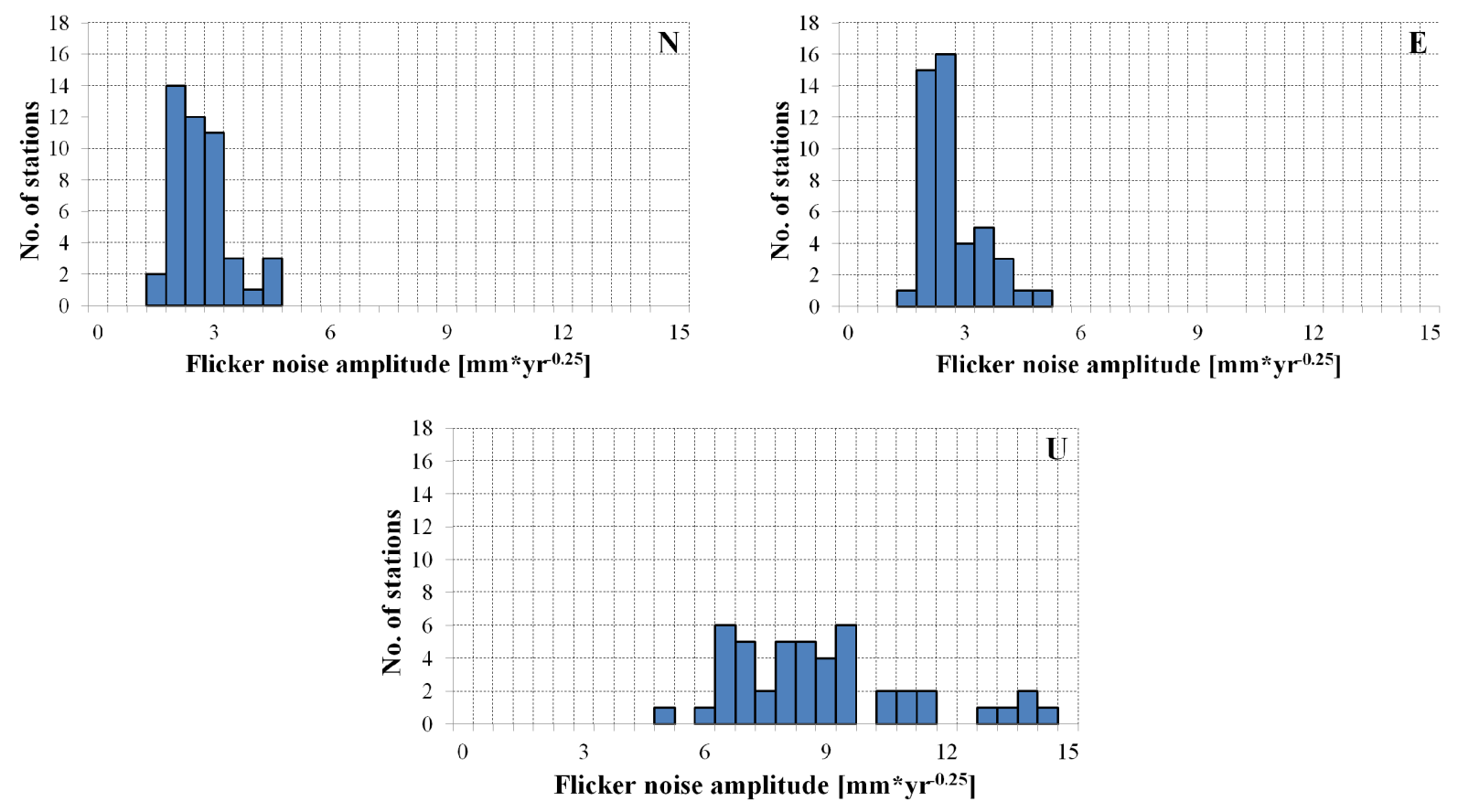

Fig. 3 The histograms of the flicker noise amplitudes $\left[\mathrm{mm}^{*} \mathrm{yr}^{-0.25}\right]-$ the North, East and Up components.

The assumption of occurrence of only white noise in the time series of the topocentric components is too optimistic. It assumes that the stochastic part does not include any information and it is not timecorrelated. With this assumption, the uncertainty of permanent station velocity has the smallest value, due to the fact that it is dependent only on the amplitude of white noise $a$, number of observations $N$ and the total time span $T$ (Zhang et al., 1997):

$\sigma_{r}^{2}=\frac{12 a^{2}}{N T^{2}}$

The amplitudes of the white noise for the Sudeten-located stations range from 0.6 to $2 \mathrm{~mm}$ for the horizontal and from 2 to $8 \mathrm{~mm}$ for the vertical component, while the velocity uncertainties ranges from 0.01 to $0.13 \mathrm{~mm} /$ year for the horizontal velocities and from 0.04 to $0.24 \mathrm{~mm} /$ year for the vertical one. It means that in the most extreme case the velocity error for the stations located in the Sudeten region exceeds the velocity stability limit assumed by Gross et al. (2009) more than twice. The assumption of only white noise leads to the underestimation of the velocity uncertainties by the factor of 2 up to even 11 (e.g. Johnson and Agnew, 1995; Zhang et al., 1997; Mao et al., 1999; Williams et al., 2004; Kenyeres and Bruyninx, 2009).

The uncertainties of GPS-derived coordinates are the result of the imperfect models related to the satellites, the propagation media or the receiver units (Bergstrand et al., 2007). These errors are described very well by the power-law noise. The various cases of it are: the white, flicker and random-walk noise for which the amplitude has to be determined. Mao et al. (1999), Williams et al. (2004) and Calais (1999) proved that combination of the white and flicker noises describes in the best way the noise in the GPS coordinates. Beavan (2005) showed the differences between the characteristics of noises for the time series of stations located on the concrete pillar monuments and the deep drilled braced monuments. It turned out that the instability of the antenna mounting is a serious source of noises, described very well by the random-walk process (e.g. Johnson and Agnew, 1995; Klos et al., 2014). Of course, it depends on the length of the time series, sampling interval as well as kinds and amplitudes of other noises whether it is detected in the data or not. Having this in mind, the authors examined the second combination of noises: the white, flicker and random-walk noise (Figs. 2, 3). Here, the covariance matrix of observations is created following the equation (6). The white noise is at the same level in the entire analyzed area, while the flicker noise prevails over other kinds of noises for all components. For the North and East components its amplitude ranges from 2 to $5 \mathrm{~mm}^{*} \mathrm{yr}^{-0.25}$, while for the $\mathrm{Up}$ one it is 2-3 times larger. The flicker noise is considered to be uniform for regional networks. Its amplitude may be reduced by applying the spatial and temporal filtration and removing the common mode error (CME) (Nikolaidis, 2002; Dong et al., 2006) in this way. Some of the stations show the random-walk noise amplitudes of a few millimetres. It may be the effect of their improper mounting. The undetected random-walk amplitudes in other stations' time series should not be interpreted as the deficiency in its existence. King and Williams (2009) showed that the 

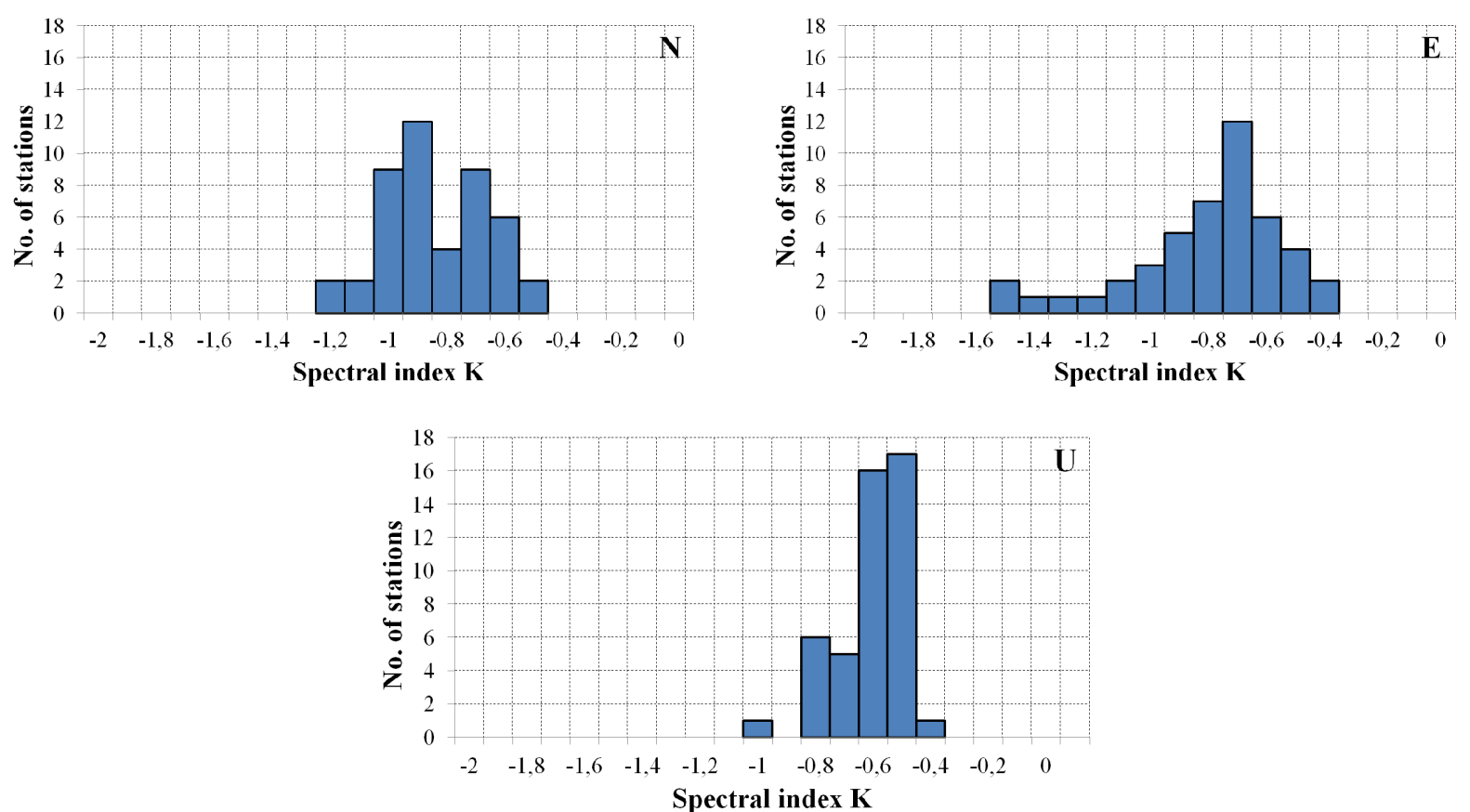

Fig. 4 The histograms of the spectral indices $\kappa$ for the North, East and Up components for stations situated in the Sudeten area.

random-walk noise amplitude is so small (not greater that $0.5 \mathrm{~mm}^{*} \mathrm{yr}^{-0.5}$ ) that it may be covered by larger amplitudes of the flicker and white noises. No spatial dependencies were discovered here for the white, flicker or random-walk noise amplitudes. It is possible that the Sudeten area that is extend only for $4^{\circ}$ in latitude and $6^{\circ}$ in longitude is too small for detecting any spatial dependencies. For the discussed combination of noises (the white plus flicker plus random-walk), the permanent stations velocity uncertainty ranges from $0.1 \mathrm{~mm} / \mathrm{year}$ for the horizontal components to even $1.1 \mathrm{~mm} /$ year for the vertical one, which is 10 times greater than the stability level of permanent stations velocity assumed by Gross et al. (2009).

The third combination of noises: the white and power-law (Figs. 4, 5) enabled to assess the optimal model and its parameters to fit the stochastic part. Williams et al. (2004) assumed the existence of the white and power-law noise combination in the GPS time series, trying to apply the MLE model which would represent the character of the stochastic part of the series. They obtained the results showing that this noise is described by the flicker noise in the best way. Santamaria-Gomez et al. (2011) determined noises for 275 permanent stations worldwide. They proved that noises in GPS observations are described in the best way by a combination of white and power-law noises with the mean amplitudes of 2 and $6 \mathrm{~mm}$. For this assumption of noises, the uncertainties of the determined velocities increased 4-5 times in comparison with the assumption of the uncorrelated stochastic part. For the Sudeten area, the obtained spectral indices range from -1.6 to -0.4 for the horizontal components and from -1 to -0.4 for the vertical one, what confirms the prevalence of fractional white and Brownian motion quite close to flicker noise $(\kappa=-1)$ with the amplitudes of 2$5 \mathrm{~mm}^{*} \mathrm{yr}^{\kappa / 4}$ and $4-12 \mathrm{~mm}^{*} \mathrm{yr}^{\kappa / 4}$ in the GPS components, respectively. For this combination of noises, the errors of the estimated velocities reach in the most extreme case even $0.8 \mathrm{~mm} /$ year for the Up component, which is 8 times larger than the assumed stability level by Gross et al. (2009) for the velocities of permanent stations used for further geodynamic analyses or kinematic reference frame maintenance.

\section{CONCLUDING REMARKS}

We compared the uncertainties of velocities assuming three combinations of noises (white noise; white, flicker and random-walk noise; white and power-law noise) (Fig. 6, Table 1).

The assumption that data are not correlated from each other (the stochastic part represents only the white noise) made the uncertainties of permanent stations velocity to exceed the stability level assumed by Gross et al. (2009) only in a few cases for the Up component. The time-correlated noise was also introduced to the computations (a combination of white and power-law noises) what resulted in the increase of the velocity uncertainties. In this case, from the set of more than 40 stations with 5 years of observations, only a few of them (20-30\% of stations for horizontal and only $2 \%$ for vertical component) reach the value of the velocity uncertainty below $0.1 \mathrm{~mm} /$ year for the North and East components, and 

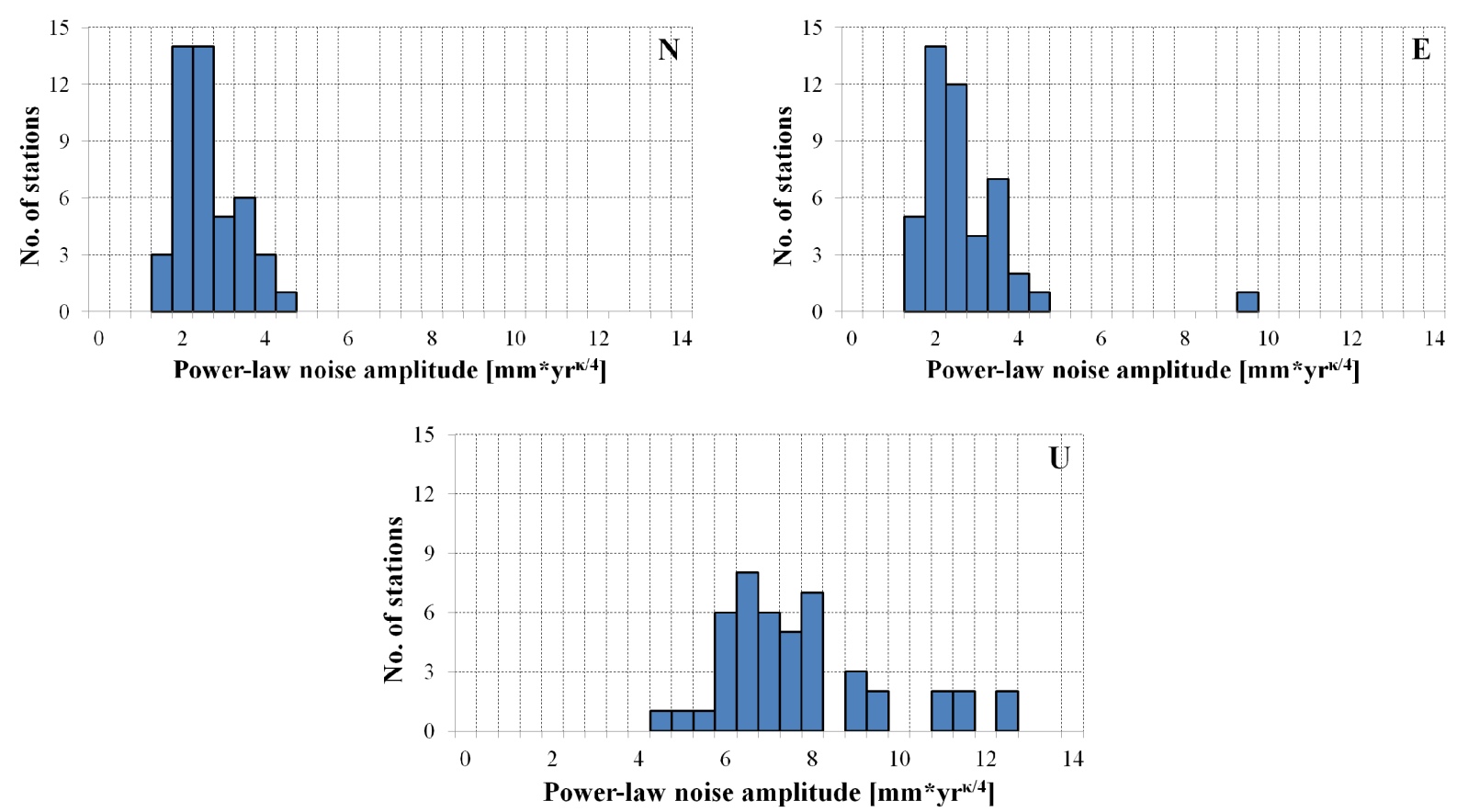

Fig. 5 The power-law noise amplitudes $\left[\mathrm{mm}^{*} \mathrm{yr}^{\kappa / 4}\right]$ for the North, East and Up components.

Table 1 The minimum, maximum and mean velocity uncertainties [mm/yr] of permanent GPS stations situated in the Sudeten region for the North, East and Up components. WN stands for the white noise, $\mathrm{WN}+\mathrm{FL}+\mathrm{RW}$ for the white, flicker and random-walk noise combination, WN+PL for the white and power-law noise combination.

\begin{tabular}{l|ccc|ccc|ccc}
\hline Noise combination & \multicolumn{3}{|c|}{ WN } & \multicolumn{3}{c|}{ WN+FL+RW } & \multicolumn{3}{c}{ WN+PL } \\
\hline Component & North & East & Up & North & East & Up & North & East & Up \\
\hline Minimum & 0.01 & 0.01 & 0.04 & 0.01 & 0.10 & 0.17 & 0.05 & 0.07 & 0.08 \\
Maximum & 0.08 & 0.13 & 0.24 & 0.60 & 1.18 & 1.20 & 0.40 & 1.10 & 0.83 \\
Mean & 0.02 & 0.02 & 0.17 & 0.22 & 0.25 & 0.51 & 0.15 & 0.17 & 0.33 \\
\hline
\end{tabular}

just one station for the Up component. The largest uncertainties occurred for the combination of white, flicker and random-walk noises. It means that assuming the white noise causes the underestimation of velocity uncertainty of permanent stations from the region of the Sudeten by a factor of almost 10 . From the two time-correlated noise combinations - white and power-law noise and white, flicker and randomwalk noise - the former with mean spectral index estimated as closer to -0.8 than -1 resulted in smaller uncertainty of the stations velocities. However, it is worth considering whether assuming of only powerlaw noise may simplify the potential causes of noise occurrence too much and exclude random-walk noise from further analyses only because the flicker noise prevails in the data. Our analyses showed that the discussed area of the Sudeten is not characterized by significant amplitudes of random-walk noise considered as the effect of improperly mounted GPS antennae. The amplitudes of a few millimetres were obtained for only some of the analyzed stations. According to Beavan (2005), when considering the random-walk noise amplitude of the level of $0.3 \mathrm{~mm}^{*} \mathrm{yr}^{-0.5}$, we understand that the antennae change their position by $0.3 \mathrm{~mm}$ during one year, and by $1.2 \mathrm{~mm}$ in 16 years of observations. On the other hand, to detect random-walk noise with the amplitude of $0.4 \mathrm{~mm}^{*} \mathrm{yr}^{-0.5}$ in the data, the series should be at least 30 years long (Williams et al., 2004). In our case, for the 5 years period of data, the detection of randomwalk noise is not reliable enough and it should not be interpreted as a poor stability of antennae mounting. As for the obtained velocity uncertainties, when selecting a noise model for the analyzed data, we should focus on the most reliable assessment of the noise model, so that the permanent stations velocities - used as the input data for further analyses - would describe the reality in the most adequate way. The values the velocity uncertainties may be underestimated by range in general from 2 to 11 times depending on the assumed noise model (e.g. Johnson and Agnew, 1995; Zhang et al., 1997; Mao et al., 1999; Williams et al., 2004; Kenyeres and Bruyninx, 2009), while for the considered regional network of 
5 years of observations the velocity uncertainties underestimation ranges from 2 to 10 times. Basing on the formula from Bos et al. (2008), to reach the goal of $0.1 \mathrm{~mm} / \mathrm{yr}$ for velocity uncertainty with the maximum amplitude of flicker noise equal to $5 \mathrm{~mm}^{*} \mathrm{yr}^{-0.25}$ (as for Sudeten stations in this research), the analysed data should have the length of at least 18 years. At the end of the research, the maximum likelihood values were compared for $\mathrm{WN}$, $\mathrm{WN}+\mathrm{FL}+\mathrm{RW}$ and $\mathrm{WN}+\mathrm{PL}$ noise models. It seems that the white plus power-law noise has the greater values of MLE for each of analyzed stations. It indicates that the white plus power-law noise model should be used for the modelling of the stochastic part of GPS time series. The authors believe, that subtracting of the common mode error from the ASGEUPOS stations in the nearest future will bring the reduction in the flicker noise amplitudes providing the shorter time span to meet the requirements of $0.1 \mathrm{~mm} /$ year by Polish permanent stations in the same way.

\section{ACKNOWLEDGMENTS}

This research was financed by the Faculty of Civil Engineering and Geodesy MUT statutory research.

\section{REFERENCES}

Agnew, D.C.: 1992, The time-domain behaviour of powerlaw noises. Geophysical Research Letters, 19, No. 4, 333-336.

Allen, M.R. and Robertson, A.W.: 1996, Distinguishing modulated oscillations from coloured noise in multivariate datasets. Climate Dynamics 12, 772-786. DOI: $10.1007 / \mathrm{s} 003820050142$

Altamimi, Z., Collilieux, X. and Metivier, L.: 2011, ITRF2008: an improved solution of the International Terrestrial Reference Frame. Journal of Geodesy, 85, No. 8, 457-473. DOI: 10.1007/s00190-011-0444-4

Beavan, J.: 2005, Noise properties of continuous GPS data from concrete pillar geodetic monuments in New Zealand and comparison with data from U.S. deep drilled braced monuments. Journal of Geophysical Research, 110, B08410. DOI: 10.1029/2005JB003642

Beran, J.: 1994, Statistics for Long-Memory Processes, Monogr. Stat. Appl. Probab., vol. 61, 315 pp. Chapman and Hall, New York.

Bergstrand, S., Schnereck, H.-G., Lidberg M. and Johansson, J.M.: 2007, BIFROST: Noise properties of GPS time series. Dynamic Planet, International Association of Geodesy Symposia, 130, 123-130. DOI: $10.1007 / 978-3-540-49350-120$

Bogusz, J. and Kontny, B.: 2011, Estimation of sub-diurnal noise level in GPS time series. Acta Geodyn Geomater., 8, No. 3 (163), 273-281.

Bos, M.S., Fernandes, R.M.S., Williams, S.D.P. and Bastos, L.: 2008, Fast error analysis of continuous GPS observations. J. Geod., 82, 157-166. DOI: $10.1007 / \mathrm{s} 00190-007-0165-\mathrm{x}$

Bosy, J., Graszka, W. and Leończyk, M.: 2007, ASGEUPOS - a Multifunctional Precise Satellite Positioning System in Poland. International Journal on
Marine Navigation and Safety of Sea Transportation, 7(4), 371-374.

Bosy, J., Oruba, A., Graszka, W., Leończyk, M. and Ryczowolski, M.: 2008, ASG-EUPOS densification of EUREF Permanent Network on the territory of Poland. Reports on Geodesy, 2(85), 105-112.

Broomhead, D. and King, G.P.: 1986, Extracting qualitative dynamics from experimental data. Physica D: Nonlinear Phenomena 20, 217-236.

DOI: 10.1016/0167-2789(86)90031-X

Bruyninx, C., Altamimi, Z., Caporali, A., Kenyeres, A., Lidberg, M., Stangl, G. and Torres, J.A.: 2009, Guidelines for EUREF Densifications. $\mathrm{ftp}: / /$ epncb.oma.be/pub/general/Guidelines_for EUREF_Densifications.pdf

Calais, E.: 1999, Continuous GPS measurements across the western Alps, 1996-1998. Geophys. J. Int., 138, $221-$ 230. DOI: 10.1046/j.1365-246x1999.00862.x

Dach, R., Hugentobler, U., Fridez, S. and Meindl, M. (eds.): 2007, Bernese GPS software version 5.0. Astonomical Institute, the University of Bern.

Dong, D., Fang, P., Bock, Y., Webb, F., Prawirodirdjo, L., Kedar, S. and Jamason, P.: 2006, Spatiotemporal filtering using principal component analysis and Karhunen-Loeve expansion approaches for regional GPS network analysis. Journal of Geophysical Research, 111, B03405. DOI: 10.1029/2005JB003806

Gazeaux, J., Williams, S., King, M., Bos, M., Dach, R., Deo, M., Moore, A.W., Ostini, L., Petrie, E., Roggero, M., Teferle, F.N., Olivares, G. and Webb, F.H.: 2013, Detecting offsets in GPS time series: First results from the detection of offsets in GPS experiment. Journal of Geophysical Research: Solid Earth, 118, 2397-2407. DOI: 10.1002/jgrb.50152, 2013.

Gross, R., Beutler, G. and Plag, H.-P.: 2009, Integrated scientific and societal user requirements and functional specifications for the GGOS. In: H.-G. Plag, M. Pearlman (eds.), Global Geodetic Observing System: Meeting the Requirements of a Global Society on a Changing Planet in 2020, Springer, Berlin, 209-224.

Hill, E.M., Davis, J.L., Elosegui, P., Wernicke, B.P., Malikowski, E. and Niemi, N.A.: 2009, Characterization of site-specific GPS errors using a short-baseline network of braced monuments at Yucca Mountain, southern Nevada. Journal of Geophysical Research, 114, B11402. DOI: 10.1029/2008JB006027

Ji, K.H. and Herring, T.A.: 2013, A method for detecting transient signals in GPS position time-series: smoothing and principal component analysis. Geophysical Journal International, 193, No. 1, 171186. DOI: $10.1093 /$ gji/ggt003

Johnson, H.O. and Agnew, D.C.: 1995, Monument motion and measurements of crustal velocities. Geophysical Research Letters, 22, No. 21, 2905-2908. DOI: 10.1029/95GL02661

Kenyeres, A. and Bruyninx, C.: 2009, Noise and periodic terms in the EPN time series. Geodetic Reference Frames, International Association of Geodesy Symposia, Volume 134, 143-148. DOI: $10.1007 / 978-3-642-00860-322$

King, M.A. and Williams, S.D.P.: 2009, Apparent stability of GPS monumentation from short-baseline time series. Journal of Geophysical Research, 114, B10403. DOI: 10.1029/2009JB006319 
Klos, A., Bogusz, J., Figurski, M. and Kosek, W.: 2014, Noise analysis of continuous GPS time series of selected EPN stations to investigate variations in stability of monument types. Accepted for publication in the International Association of Geodesy Symposia, proceedings of the VIII Hotine Marussi Symposium.

Langbein, J.: 2008, Noise in GPS displacement measurements from Southern California and Southern Nevada. Journal of Geophysical Research, 113, B05405. DOI: 10.1029/2007JB005247

Langbein, J.: 2012, Estimating rate uncertainty with maximum likelihood: differences between power-law and flicker-random-walk models. Journal of Geodesy, 86, 775-783. DOI: 10.1007/s00190-012-0556-5

Langbein, J. and Johnson, H.: 1997, Correlated errors in geodetic time series: Implications for time-dependent deformation. Journal of Geophysical Research, 102, No. B1, 591-603. DOI: 10.1029/96JB02945

Mao, A., Harrison, Ch.G.A. and Dixon, T.H.: 1999, Noise in GPS coordinate time series. Journal of Geophysical Research, 104, No. B2, 2797-2816.

DOI: $10.1029 / 1998 J B 900033$

Mosteller, F. and Tukey, J.: 1977, Data Analysis and Regression. Upper Saddle River, NJ: AddisonWesley.

Nikolaidis, R.: 2002, Observation of geodetic and seismic deformation with the Global Positioning System. Ph.D. thesis, Univ. of Calif., San Diego.

Rodionov, S.: 2004, A sequential algorithm for testing climate regime shifts. Geophysical Research Letters, 31, L09204. DOI: 10.1029/2004GL019448

Rodionov, S. and Overland, J.E.: 2005, Application of a sequential regime shift detection method to the Bering Sea ecosystem. ICES Journal of Marine Science, 62, 328-332. DOI: 10.1016/j.icesjms.2005.01.013.

Sachs, L.: 1984, Applied Statistics: A Handbook of Techniques. New York: Springer-Verlag, pp. 253.

Santamaria-Gomez, A., Bouin, M.-N., Collilieux, X. and Woppelmann, G.: 2011, Correlated errors in GPS position time series: Implications for velocity estimates. Journal of Geophysical Research, 116, B01405. DOI: 10.1029/2010JB007701
Szafranek, K., Bogusz, J. and Figurski, M.: 2013, GNSS reference solution for permanent station stability monitoring and geodynamical investigations: the ASG-EUPOS case study. Acta Geodyn. Geomater., 10, No. 1 (169), 67-75. DOI: 10.13168/AGG.2013.0006

Teferle, F.N., Williams, S.D.P., Kierulf, K.P., Bingley, R.M. and Plag, H.P.: 2008, A continuous GPS coordinate time series analysis strategy for high-accuracy vertical land movements. Physics and Chemistry of the Earth, 33, 205-216. DOI: 10.1016/j.pce.2006.11.002

Wang, W., Zhao, B., Wang, Q. and Yang, S.: 2012, Noise analysis of continuous GPS coordinate time series for CMONOC. Advances in Space Research 49, 943-956. DOI: 10.1016/j.asr.2011.11.032

Williams, S.D.P.: 2008, CATS: GPS coordinate time series analysis software. GPS Solutions 12, 147-153. DOI: 10.1007/s10291-007-0086-4

Williams, S.D.P., Bock, Y., Fang, P., Jamason, P., Nikolaidis, R.M., Prawirodirdjo, L., Miller, M. and Johnson, D.: 2004, Error analysis of continuous GPS position time series. Journal of Geophysical Research, 109, B03412. DOI: 10.1029/2003JB002741

Williams, S.D.P. and Willis, P.: 2006, Error analysis of weekly station coordinates in the DORIS network. Journal of Geodesy 80, 525-539. DOI: 10.1007/s00190-006-0056-6

Zhang, J., Bock, Y., Johnson, H., Fang, P., Williams, S., Genrich, J., Wdowinski, S. and Behr. J.: 1997, Southern California Permanent GPS Geodetic Array: Error analysis of daily position estimates and site velocities. Journal of Geophysical Research, 102, No. B8, 18035-18055. 

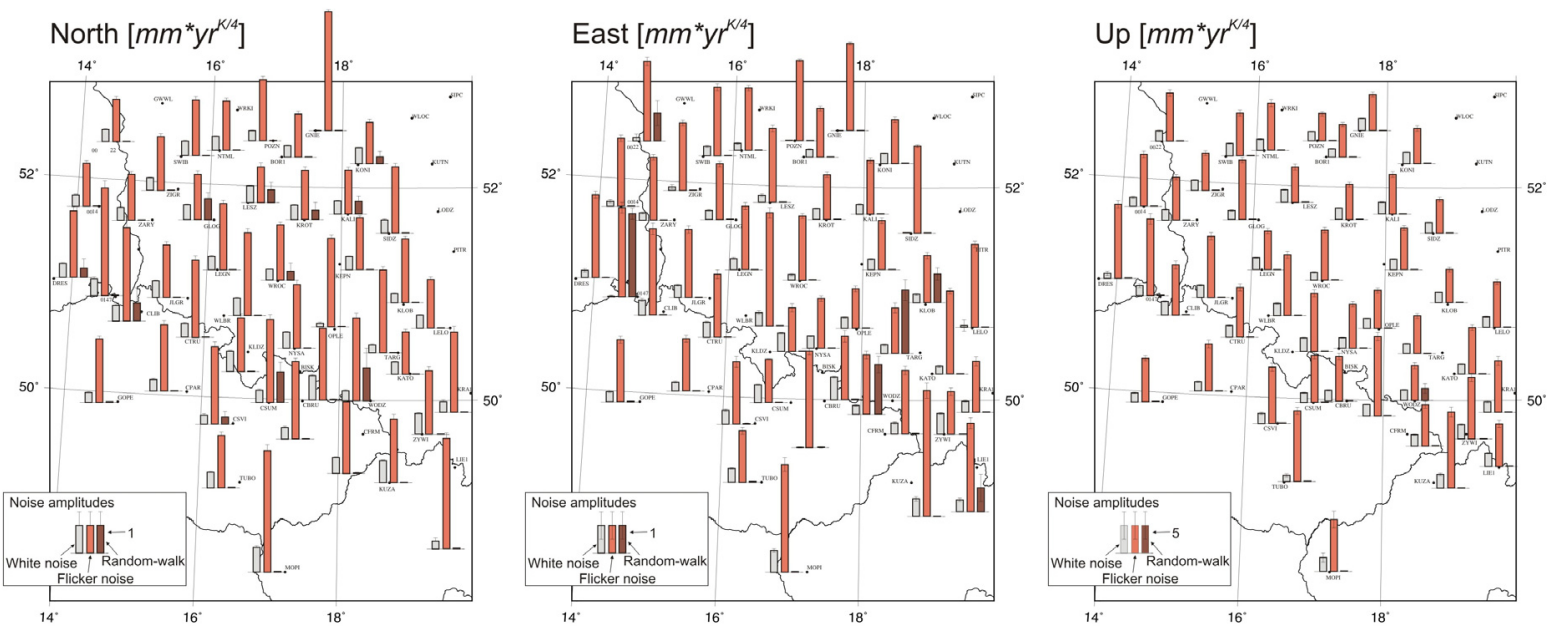

Fig. 3 The noise amplitudes: white (marked with grey), flicker (marked with pink) and random-walk (marked with brown) for the ASG-EUPOS stations and selected EPN stations in the area of the Sudeten. The amplitudes are given in $\left[\mathrm{mm}^{*} \mathrm{yr}^{r / 4}\right]$. The scale for the Up component is 5 times smaller than for the North and East ones.
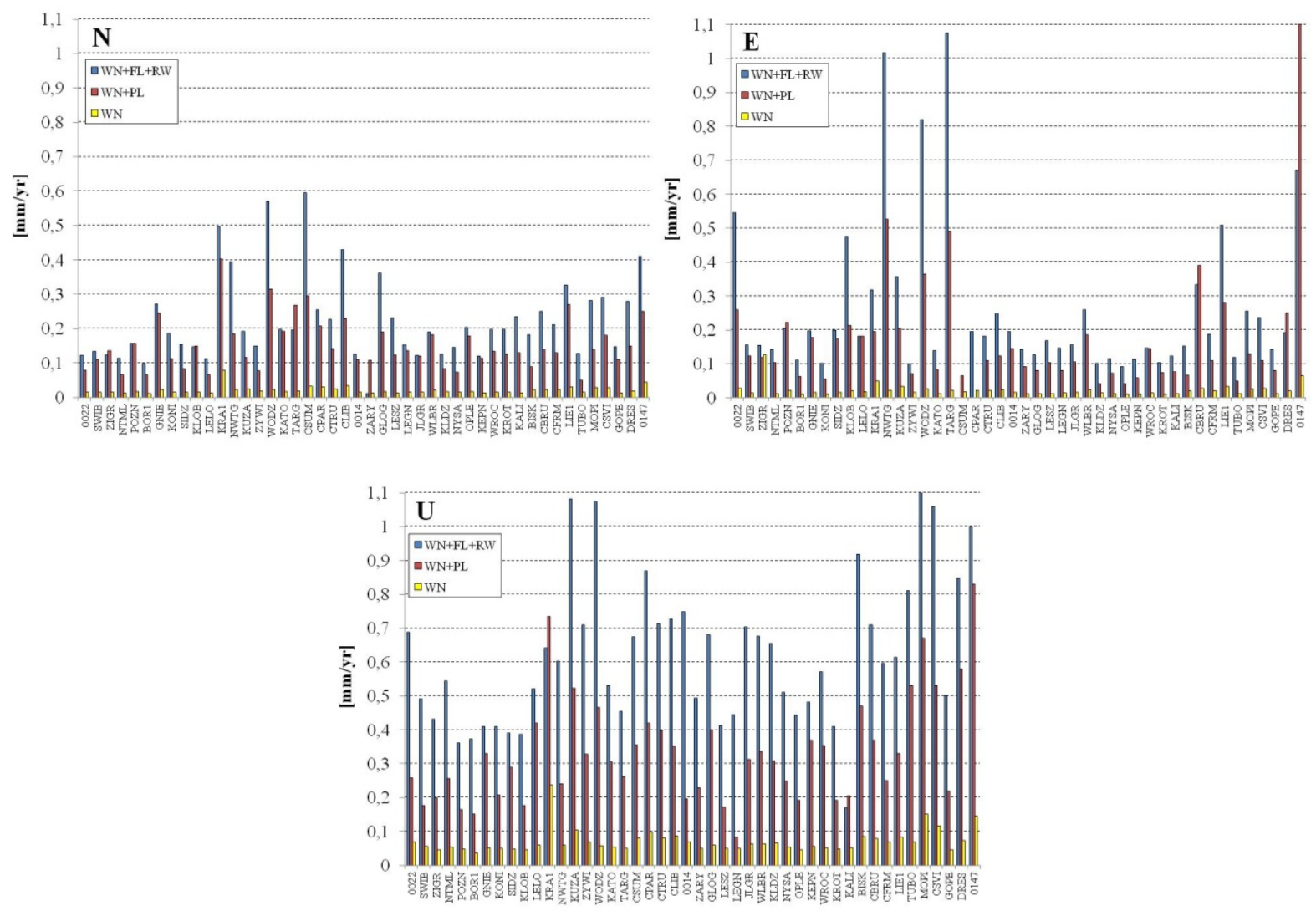

Fig. 6 The velocity uncertainties [mm/yr] of permanent GPS stations situated in the Sudeten region for the North, East and Up components. The uncertainties for the white noise are presented in yellow (WN); the uncertainties for the white, flicker and random-walk noise combination are presented in blue $(\mathrm{WN}+\mathrm{FL}+\mathrm{RW})$; uncertainties for the white and power-law noise combination are presented in red $(\mathrm{WN}+\mathrm{PL})$. 